\title{
Application of ANN to Predict S.I. Engine Performance and Emission
} Characteristics Fuelled Bioethanol

\author{
T. SARAVANA Kannan ${ }^{1, a}$, ABU Saleh Ahmed ${ }^{2,}$ and F.N. Ani ${ }^{3, c}$ \\ ${ }^{1}$ Faculty of Engineering, Computing and Science, Swinburne University of Technology, Kuching, \\ Sarawak, Malaysia \\ ${ }^{2}$ Department of Mechanical and Manufacturing Engineering, Faculty of Engineering, Universiti \\ Malaysia Sarawak, Sarawak, Malaysia \\ ${ }^{3}$ Faculty of Mechanical Engineering, UniversitiTeknologi Malaysia, Skudai, Johor D.T., Malaysia \\ asthangavelu@swinburne.edu.my, ${ }^{b}$ aasaleh@feng.unimas.my, ${ }^{c}$ farid@fkm.utm.my
}

Keywords: S.I engine, bioethanol, ANN, performance, emission

\begin{abstract}
The performance of artificial neural network (ANN) to predict spark ignition (S.I) engine performance such as torque, BSFC, exhaust temperature and emissions (CO and $\mathrm{HC}$ ) for various compression ratios was investigated.For training and testing the $\mathrm{ANN}$, experimental data from a single cylinder Hydra spark ignition engine powered by various bioethanol and gasoline blends (E0, E10, E20, E40 and E60) were used. ANN performance was measured by mean squared errors and correlation coefficient. The training function used was trainbr and the training algorithm used was feed-forward back propagation. The overall correlation coefficient obtained from the prediction was 0.98526 and the mean squared error obtained was very low (9.26E-06).
\end{abstract}

\section{Introduction}

Artificial neural networks (ANN) are used to solve awide variety of problems in science and engineering, particularly for some areas where the conventional modeling methods fail. A well-trained ANN can be used as a predictive model for a specific application, which is a data-processing system inspired by biological neural system. The predictive ability of an ANN results from the training on experimental data and then validation by independent data. An ANN has the ability to re-learn to improve its performance if new data are available [1]. Many researchers used ANN to predict internal combustion engine performance and emission characteristics. Most of studies were done in diesel engine using biodiesel and petro-diesel blends [2, 5]. Very few studies were performed in gasoline engine using bioethanol and gasoline blends in spark ignition (S.I) engines. Kianiet al. [3] studied the neural network model for predicting the brake power, torque and the emissions of carbon monoxide $(\mathrm{CO})$, carbon dioxide $\left(\mathrm{CO}_{2}\right)$, unburned hydrocarbon $(\mathrm{HC})$ and nitrogen oxides (NOx) of the engine in relation to input variables including engine speed, engine load and fuel blends. Najafiet al. [4] used the ANN to determine the engine power, torque, brake specific fuel consumption, brake thermal efficiency, volumetric efficiency and emission components based on different gasoline-ethanol blends and speeds using results of experimental analysis. In this work, an ANN model was developed for single cylinder Hydra spark ignition (S.I) engines, powered using various blends of bioethanol-unleaded petrol to predict engine performance and engine emissions using various compression ratio, engine speed and various blends of bioethanol-unleaded gasoline blends. The proximity of ANN's prediction with the experimental results was also compared.

\section{Experimental Work and Data Collection}

Experiment Setup and Procedure In this study, a single cylinder Hydra spark ignition engine was used. The experimental data were collected from the work done by Yücesuet al.[6].The experiments were carried out with three constant engine speed of 2000, 3500 and $5000 \mathrm{rpm}$ with six compression ratio varied from 8:1 to $13: 1$ for each case. The fuel blends tested were E0, E10, E20,E40 and E60 which indicated the percentage of volumetric amount of ethanol. The effect of 